\title{
REPRESENTACIONES GENÉRICAS EN EL TEATRO SANTAFESINO DE INMIGRACIÓN ITALIANA. Una propuesta de lectura desde el marco de los estudios comparados.
}

\author{
Adriana Cristina Crolla \\ Univ. Nac. del Litoral
}

En oportunidad de un encuentro de italianistas en una sede española ${ }^{1}$ en que nos interesaba proponer un cierto perfil individualizador de nuestra idiosincrasia, recordamos una idea expresada alguna vez por Jorge Luis Borges quien afirmó que la identidad argentina no debe ser buscada en su pasado indígena sino en la cultura occidental ya que a los argentinos se los debe considerar "europeos en el exilio". De hecho, la magnifica corriente inmigratoria que conformó nuestra etnia hace que la Argentina se destaque, en el contexto de las demás naciones hispanoamericanas, como la más ecléctica y europea de todas.

Los escritores, voces que dan cuerpo a un entramado de bienes espirituales no mensurables y que constituyen el patrimonio total que Europa nos transmitió, ejercen su particular mirada sobre este desarraigo esencial que nos hace sentirnos disociados aún en nuestra propia tierra:

"żCuál es mi patria? "se pregunta, consternado, Ernesto Sábato para agregar, "Crecimos bebiendo la nostalgia europea de nuestros padres, oyendo de la tierra lejana, de sus mitos y cuentos, viendo casi sus montañas y sus mares. Lágrimas de emoción nos han caído cuando por primera vez vimos las piedras de Florencia y el azul del Mediterráneo, sintiendo de pronto que centenares de años y oscuros antepasados latían misteriosamente en el fondo de nuestras almas" . (pero) "...también, en momentos de soledad en aquellas ciudades (italianas), sentimos que nuestra tierra era ésta, estaba acá en la pampa y en el vasto rio, pues la patria no es sólo la infancia, algunos rostros, algunos recuerdos de adolescencia, un árbol de barrio, una insignificante calle, un viejo tango en un organito, el silbato de una locomotora de manisero en una tarde de invierno, el olor (el recuerdo del olor) de nuestro viejo motor en el molino, un juego de barriletes. ¿Y cómo esta novela puede ser simple o nítida, o folklórica o pintoresca? ${ }^{, 2}$

Los argentinos somos productos de la diáspora y de la mezcla. Nuestra idiosincrasia condiciona nuestro ser y nuestra producción cultural a un esencial eclecticismo que nos obliga a indagar como recurrente leit motiv los rasgos que tipifican nuestra elusiva identidad . Crisol aluvional que nos proporciona ese sello de universalidad que nos hace más abiertos y sensibles a todas las etnias y culturas y nos genera una marcada tendencia a desrealizar la realidad del aquí para proyectarnos utópicamente a espacios invariablemente distantes y siempre distintos del natal. Es esta duplicidad la que hace al tango quejumbroso y melancólico, siempre llorando el omphalos perdido (la "querida viejita" abandonada), siempre fascinado por lo nuevo y lo

\footnotetext{
${ }^{1}$ VII Congreso Nacional de Italianistas. "El teatro italiano". Valencia, España. Octubre 1996. Algunos tramos del presente trabajo fueron presentados en esa oportunidad y constan en las Actas correspondientes.

2 Sábato, Ernesto: "El escritor y sus fantasmas"
} 
foráneo, con irremediable deseos de "irse" (del conventillo, el barrio, la ciudad) y cuando lo ha hecho, llorando por "volver". 3

De allí nuestra peculiar e intrínseca disociación al sentirnos europeos exiliados en nuestro propio suelo. $\mathrm{Y}$, por contrapartida, nuestra versatilidad y capacidad para sentirnos ciudadanos del mundo, y para comprender el influjo que Europa, en especial Italia (también en el tiempo-espacio franco de la latinidad) y su inmenso aluvión inmigratorio, ha ejercido y ejerce en nuestra conformación cultural.

Felix Luna asi lo certifica: "No corre por mis venas una sola gota de sangre italiana. Por vía paterna vengo de una familia de origen castellano ... y por el lado materno mi abuelo era asturiano....Y sin embargo "qué cálida vibración tiene en mi espiritu todo lo que tiene que ver con Italia....Es que toda la cultura occidental está impregnada por la impronta histórica surgida de Roma. Por más rico y plural que pueda ser el estilo cultural de un pueblo de Occidente, alli está, en la superficie, o un poco más abajo, la realidad latina, italiana, romana. En el arte, la música, la legislación, la arquitectura, las letras, la fisonomía urbana, las formas de vida. Entonces, es lógico, que todos nos reencontremos alguna vez en esa enorme matriz que es el legado de Italia"

\section{VOCES DE LA ITALIANIDAD EN LA DRAMATURGIA SANTAFESINA}

La cultura italiana como fenómeno histórico y social fue trasplantada a nuestra tierra en los recuerdos, costumbres y dialectos, de la inmensa masa de inmigrantes que ingresaron por oleadas a la Argentina. Esta fuerza étnica provocará cambios sustanciales en el esquema social autóctono (indio-hispánico) dando origen a lo que se conoce, especialmente en relación con las colonias fundadas en suelo santafesino, como PAMPA GRINGA.

Sin embargo, su influencia en la literatura argentina no será, durante largos períodos, tan evidente como el aporte francés. El influjo italiano es más sutil y difuso, se trata de una verdadera corriente sanguínea que alimenta, como una red subterránea de sabia nutriente, la obra de la mayor parte de nuestros autores, en muchos casos sin que ese sustrato, sea visible en la superficie. El habla rioplatense, y en fuerte medida, la santafesina, sus costumbres, su narrativa, lírica y teatro están impregnados de esa influencia y basta sólo un análisis atento, para hacer manifiestas esas huellas.

Tomando como objeto de estudio obras dramáticas emergentes de la producción literaria de descendientes de aquella "gesta gringa", nos será posible analizar marcas que definen una particular visión de la realidad. Entendemos que la presencia de la italianidad operó como un masivo sistema de resignificación que aportó, a partir del proceso histórico de

\footnotetext{
${ }^{3}$ Roberto Cossa sostiene que: "El tema clave es el de los argentinos, que en mi es un tema recurrente, el de la frustración, el de la irrealidad, ese inventarse un país que no existe. Un sentimiento que va acumulando frustraciones y creando mitos" refiriéndose a los mitos de la inmigración, del éxito Gardel, y todos los mitos del tango, la Europa culta y de lo foráneo utópico. Sayaz de Lima, Perla: Diccionario de autores teatrales argentinos. Ed.Galerna,Bs As, 1991

4 Revista: "Todo es historia". : ITALIA: la otra madre patria nro. 305, pag 6. Diciembre 1992 Soc. Impresora Americana \$A. Bs As. Argentina
} 
ocupación del espacio pampeano, factores culturales que contribuyeron a conformar la actual sociedad.

Indagando en la esforzada migración del extranjero italiano por la pampa, que se va haciendo gringa a su paso, es posible detectar aquellos códigos sémicos que constituyen el eje matricial de la ITALIANIDAD, ya sea en valores sustancialmente positivos como ser: un concepto aglutinante de familia, valorativa concepción del trabajo, marcada tendencia al gregarismo endogámico y al mantenimiento y trasmisión de las tradiciones de origen, valor nucleante de la maternidad, respeto a los manes ${ }^{5}$, a la identidad lingüística, espíritu estoico y vocación para el canto.

Pero también disvalores que podemos fácilmente reconocer como tipificantes en muchas de nuestras prácticas sociales regionales y, por extensión, de la argentinidad rioplatense, originados alli donde las virtudes y los buenos valores se exacerban perdiendo su inicial positividad.

Por ejemplo, un excesivo, unilateral y reverencial respeto a la "autorictas" (los manes), simbolizada en la figura paterna permite explicar el machismo tan arraigado todavía en nuestras matrices y nuestras prácticas sociales.

El culto a la maternidad, pudo ser la causa de una idealización exacerbada de lo femenino y una absoluta incapacidad de ver a cada mujer en su individual y real concretización. En la mujer se veneraba a LA MADRE y cada madre actuaba según estos patrones modélicos. Por ello, será justamente la mujer-madre la que subliminalmente contribuirá a reproducir tanto en los hijos varones como en la mujeres, estos mismos estereotipos, determinando y ejerciendo sobre ellos un a veces excesivo control afectivo. $Y$, cuando las circunstancias lo favorecieron (muerte o desaparición temprana de la figura paterna) su rigidez moral pudo dejar huellas traumáticas indelebles, tanto en uno como en otros.

La tacañería, la usura, derivó generalmente (sobre todo en la idiosincrasia de los piemonteses) de un fuerte verticalismo y concepción materialista de la existencia. Particularmente en este grupo social que se caracterizó por concebir el trabajo, el ahorro y la actitud estoica ante las adversidades como única respuesta a la búsqueda de un progreso que asegurara un futuro mejor a las generaciones venideras.

Estos inmigrantes vinieron a "Hacer la América" para sus hijos, pero, su temor a la pobreza y su necesidad de afianzar (e incrementar) el pequeño "tesoro" que iban construyendo, provocó, paradójicamente, que estos mismos hijos no pudieran gozar durante toda su vida de la bonanza que progresivamente se iba consolidando. El control de la riqueza permanecía hasta su muerte en manos del pater familias siendo la causa de no pocas tragedias, disensiones entre hermanos o incapacidad para insertarse operativamente en la realidad.

Todo ello agravado por un particular respeto y sumisión a los mandatos del entorno social que la fuerte endogamia de las mismas "colonias", colaboró a potenciar.

Proponemos entonces un análisis para visualizar la forma cómo algunas de estas manifestaciones se resignifican en obras dramáticas de escritores santafesinos que, ficcionalizando momentos históricos diferentes, reflejan el lento y doloroso proceso de

\footnotetext{
${ }^{5}$ MANES: en la cultura romana, así se llamaba a los genios del mundo subterráneo que representan las almas de los antepasados que tutelan con su presencia la paz y el bienestar de la casa y de la familia
} 
simbiosis de los patrones culturales aportados por los inmigrantes y su dificultosa adaptación a las conflictivas realidades autóctonas.

Es necesario acotar que las tres obras seleccionadas responden al proceso inmigratorio en el contexto rural y se enmarcan en un recorte temporal que va desde comienzos de siglo hasta el comienzo en la década del 40 de las diásporas del campo a la ciudad.

No se abordará por tanto, la particular representación que asumió la radicación de estos grupos en el contexto ciudadano. Proceso de interculturación que, en la gran urbe de Buenos Aires, contribuyó al surgimiento de una manifestación musical autóctona: el tango y de jergas: el lunfardo (discurso de los marginales) y el cocoliche: parodia de la "parlata" itañola. Problemática abundantemente tratada ya en el "sainete" o teatro del grotesco porteño y ampliamente estudiada en relación con el teatro pirandelliano y la comedia moderna italiana, donde se caricaturizó la figura del inmigrante mostrándolo frecuentemente en un proceso irreversible de inadaptación y degradación .

\section{DATOS PARCIALES DEL PROCESO INMIGRATORIO EN LA PAMPA SANTAFESINA}

Dos siglos después de iniciada la conquista del territorio sudamericano por los adelantados españoles (S. XVI) el territorio pampeano controlado por la colonización española era todavía muy reducido. El Litoral (Pcias de Santa Fe y Entre Ríos) se halla prácticamente vacío de hombres y animales. En 1858 toda la llanura santafesina cuenta con sólo 25.000 habitantes frente a los 180.000 de Buenos Aires. ${ }^{6}$

Mientras la provincia de Buenos Aires empieza a separarse, Santa Fe y Córdoba apuestan a reforzar vínculos con el extranjero y en ese clima favorable se funda en 1853, en las cercanías de la ciudad de Santa Fe, la primera colonia agrícola pampeana de origen europeo: Esperanza ${ }^{7}$ con una importante conformación étnica inicial de origen suizo y alemán.

A fines de la década del sesenta, lentamente la pampa santafesina ha empezado a poblarse, cuenta ya con 17 colonias en 1869 y han llegado las primeras familias originarias del Piemonte que se van incorporando a las helvéticas en las sucesivas fundaciones. Es en esa década que se produce, gracias a la construcción de la línea ferrocarrilera, un súbito florecimiento de colonias: seis en 1869 y ocho en 1870,39 en 1876 con 23.595 personas y un cambio en la propiedad de la tierra ya que la valorización de los precios tienta a los latifundistas a venderla en parcelas a los recién llegados los que se dedicaran en general al monocultivo del cereal. Las exigencias europeas de cereales, especialmente de trigo, aumenta por esos años y

\footnotetext{
${ }^{6}$ Citado por Gaignard. Romain La Pampa Argentina, Solar Ed, pag .157

${ }^{7}$ En 1879, después de sesenta días de viaje, llegan a Esperanza los primeros colonos, todos italianos y en su casi totalidad piemonteses, convocados por Guillermo Lehmann para colonizar el territorio donde empieza a conformarse Rafaela, a $100 \mathrm{kms}$ de la capital provincial a partir de 1882. "Lehmann se da cuenta rápidamente que estos campesinos, fugitivos de la guerra, del hambre y de la miseria,,,son trabajadores incansables, modestos, dóciles, tolerantes, cerrados en si mismos, pero prontos a cantar en coro para acompañar el trabajo del campo. Sesenta y nueve familias piemontesas compran buena parte de las 448 concesiones por un total de 15.000 hectáreas. A quien compra más de un lote, Lehmann regala $10.000 \mathrm{~ms} 2$. en la ciudad. Se ha documentado que algunos piemonteses rechazaron la oferta de Lehmann quizás para evitar los gastos notariales, pero más probablemente porque querian vivir en la propia tierra para defenderla y cultivarla mejor" Agosti, Paola: Piemontesi in Argentina, "Torino magazine" nro 5, maggio 1989. De Quattro, Torino Italia. (la traducción es nuestra)
} 
ofrecen a la naciente producción de las colonias agrícolas de Santa $\mathrm{Fe}$, un enorme mercado que la navegación transatlántica ha tornado posible.

Por otro lado, comienza a desarrollarse la inmigración espontánea, estimulada directamente por las campañas sistemáticas de las compañias contratistas que difunden por Europa noticias sobre estas nuevas colonias y, en particular, por la acción de los primeros inmigrados, quienes incitan a sus parientes y amigos a dejar Italia y unírseles ante la notoria necesidad de incrementar la cantidad de brazos fuertes para el trabajo agrícola y por lógicas necesidades afectivas.

Tímidamente, empieza a nacer una Pampa gringa, ocupada por campesinos extraños al pueblo criollo y a la lengua española. Pampa doblemente extranjera tanto en su nueva población como en la nueva valoración que se hace del espacio. La economía de propiedad pastoril, enpieza a abrirse a una nueva estructura agraria y un nuevo modo de explotación familiar dedicada a los cultivos cerealeros. Y es precisamente en la Provincia de Santa $\mathrm{Fe}$, lugar de nacimiento de esta nueva forma de colonización donde esforzada y penosamente se originará esta civilización gringa que pronto cubrirá de leyenda la pampa gaucha. ${ }^{8}$

\section{SEMIOSIS DEL TEXTO DRAMATICO: PROPUESTA DE LECTURA .}

En todo texto dramático, Lectura y representación son dos fases de un mismo proceso de comunicación pero que, como "hecho de recepción", tienen diferentes receptores: con actitudes y competencias diferentes: lector/espectador.

No entraremos, pues excede las pretensiones del presente trabajo, a cotejar las variantes que se pueden señalar en ese proceso de transposición. Sí dejaremos constancia de algunos signos secundarios que colaboran para la comprensión de la problemática de análisis propuesta en relación con las marcas escriturario-culturales de la italianidad que permanecen y emergen en la producción teatral de autores santafesinos de raigambre itálica .

Desde el punto de vista metodológico, nos situaremos en el campo de lo comparatístico tratando de trasponer competencias de la Literatura Comparada: fenómenos de producción, circulación y recepción que exceden y/o interrelacionan lo "nacional" con lo "extranjero".

Dentro de esta línea, el Teatro Comparado es "una disciplina que estudia los fenómenos teatrales y la teoría teatral desde un punto de vista internacional o supranacional". Siguiendo las opiniones del estudioso Jorge Dubatti ${ }^{9}$ "la peculiaridad del Teatro Comparado radicará en la adaptación de la teoría y la práctica de la Literatura Comparada a la especificidad del lenguaje teatral. De esta manera el Teatro Comparado descubre un repertorio de problemas particulares ...y una larga lista de aspectos que deben ser sistematizados"

Entre los problemas generales a considerar, se incluye la "imagología" o estudio de la representación de "lo extranjero". En esta vertiente, la imagen construida en torno a la figura

\footnotetext{
${ }^{7}$ Bibliografia sobre inmigración:

Gori, Gastón: Inmigración y colonización en la Argentina. De Eudeba, Bs As 1988

Inmigración, identidad y cultura. Subsecretaría de Cultura de la Pcia de Sta Fe. 1991

Nueva enciclopedia de la Provincia de Santa Fe. Tomos I al IV. De Sudamericana Sta Fe

9 Dubatti, Jorge: Teatro comparado, problemas y conceptos. Univ. Nac de Lomas de Zamora. Bs As. Argentina, 1995
} 
del inmigrante en general y del italiano en particular en el teatro argentino, es de suma importancia.

En las obras mencionadas, la imagen foránea será operada desde una particular mirada: la del escritor descendiente, ya argentinizado, que no sólo construye ficcionalmente para revalorizar aquello que lo particulariza sino que, por la distancia temporal que lo separa de los ancestros y su "argentinización" comienza a operar una lectura crítica de las derivaciones negativas de esas marcas de origen.

Con respecto a la especie dramática, estas obras pueden ser clasificadas como tragicomedias, género apto para representar un rasgo definitorio del ser ( $\mathrm{y}$ por ende de la producción teatral argentina) ${ }^{10}$. Según Hegel, ambos polos: comedia y tragedia, se aproximan en la tragicomedia y se neutralizan recíprocamente: la tragedia muestra siempre un momento de ironía trágica y la comedia abre frecuentemente perspectivas inquietantes. En la tragicomedia, como en el ser argentino, se manifiestan estas tendencias disociativas, ambiguas, en un estilo, visceralmente antitético que experimenta los altibajos de lo enfático y noble con lo cotidiano y vulgar.

Estos tres textos son abordados en análisis comparativo diacrónico pues conforman un ciclo que va desde una visión más dramática y comprometida con los valores culturales de la italianidad, hasta una forma más ecléctica donde la tragicomedia se enriquece con aportes del realismo mágico logrando una densidad lírica no alcanzada en las dos primeras.

1. "DIS PA GNENTE" Autor: OSCAR BALBI. Estreno: San Jorge,(Pcia de Santa Fe) 1996. Guión inédito.

La importancia nuclear de la figura materna en el contexto inmigratorio aparece ya destacada a nivel paratextual en la dedicatoria inicial: "A la memoria de mi madre que tenía algo de cada una de las mujeres de esta historia"

Es importante señalar también la vigencia afectiva de esas experiencias en estas comunidades todavía hoy día como queda demostrado, (información aportada por su autordirector), en la matriz anecdótica de la historia: "esta obra fue escrita juntando todas las historias que me contaron sobre la vida de los primeros pobladores piamonteses de San Jorge. A esas viejas vivencias que guardaba en mi mente, agregué datos que saqué entrevistando a gente relacionada directamente con la época y otros consultando una variada bibliografia"; y en la masiva y entusiasta recepción que tuvo esta propuesta escénica en su ciudad de origen y en los numerosos centros culturales de la provincia donde fue montada en el corto tiempo que va desde su estreno. Así como la traducción del texto al piemontés por la Familia Piemontesa de San Jorge para ser representada durante 1996 en Italia.

\footnotetext{
10 Juan Carlos Ghiano, dramaturgo argentino afirmó en relación con su obra:

“...si he reiterado la tragicomedia es porque creo que resulta la forma más adecuada a los hábitos mentales argentinos, ni decididamente trágicos ni abiertamente cómicos. La tragicomedia, como la farsa, importan actitudes de mesura o de pudor, con las que se trata de equilibrar el impulso primero de violencia, que al final rompe con todas las imposiciones de la cautela" Ghiano, J_V: Noticia preliminar a Narcisa Garay, mujer para llorar, en "Teatro argentino contemnoráneo 1949-1969" pag. 351. Madrid, Aguilar, 1970.
} 
Si bien es la obra más nueva entre las que analizaremos (fue estrenada en junio de 1996) en San Jorge, localidad del centro oeste santafesino y de aluvión inmigratorio totalmente piemontés, desde el punto de vista de la fábula y la trama, es la más tradicional en su propuesta de lectura. Consta de 10 cuadros y un desarrollo cronológico de la fábula, con prospecciones aportadas desde el relato (texto secundario) recitado por Yaco, el hijo pródigo.

Es una historia de mujeres, de tabúes y de silencios construida a partir de la detección de formas idiosincráticas del hombre del Piemonte que si bien aportó como dijimos, valores positivos que aún hoy explican la forma de ser regional: luchador, fiero para el trabajo, con un profundo sentido de la unión familiar y el respeto a la palabra común; los rasgos negativos de su carácter: parquedad, desconfianza, conservadorismo, pesimismo, excesivo respeto a los mandatos del grupo, fueron la causa de innumerables historias de tragedias familiares.

El sentido trágico de la existencia, de fatal determinismo, se manifiesta en la necesidad de ocultar los dramas familiares a fin de mantener protegido el honor de la familia y el respeto ante la comunidad.

Madre: Los golpes que tuve en la vida me hicieron desconfiada. Es horrible ver cómo los otros se rien de uno, no hay que dar de hablar a la gente. Asi me enseñaron y asi seré hasta que muera. El Barba Yan siempre nos decía que cuidáramos el honor, porque era lo único que teníamos.

Los BENEDETTO, una familia llegada con los primeros grupos inmigratorios, no son bendecidos por el destino, como su apellido lo sugiere, sino secularmente maldecidos y lievan en sí el estigma de una culpa originaria, ocultada celosamente por la materfamilias: el padre ha sido asesinado en casa de una amante, por un marido celoso. La madre ha fraguado una mentira de robo y de heroica resistencia del marido, para así poder sobrevivir al deshonor y la vergüenza en la cerrada moral de la comunidad. En ese contexto de sumisión, de esfuerzo cotidiano en los trabajos rurales y de matrimonios sin amor, una hija, María se destaca de los demás por su espíritu vivaz, su fuerza interior y por negarse a vivir una vida de conformismo renegando del amor:

Madre: Mirá que sos fola, vos!... Qué manera de ser tan especial! Sos distinta a todos nosotros. Sos tan alegre. Me hacés acordar a mi tía Dominga que hacia todos los trabajos cantando..ojalá nunca se te borre esa sonrisa de la cara, ojalá siempre puedas ser feliz.

María se atreve a desobedecer el status quo al enamorarse de un peón que, aunque es italiano, es de otro lugar y ha venido a trabajar circunstancialmente durante la época de la cosecha :

María: Qué se yo....Usted es distinto ...No es...

Pedro Leone: Criollo? (Maria asiente) No, soy de origen italiano, igual que ustedes, pero de otro lado.

Diferente porque culto, instruido por su padre, un "casi" cura que tuvo que huir a América por haber matado a un patrón deshonesto y egoísta. 
A diferencia de los hijos de Benedetto, Pedro recuerda a su padre, puede hablar de sus defectos y reconocer sus valores. Mientras que en esta otra familia, el recuerdo del padre ha sido eliminado por la esposa burlada, que ha construido la historia familiar en base a privaciones femeninas y olvido:

Inés: No te puedo creer. Tomás tendria que haberme contado.

María: es la influencia de la mare. Ella casi nunca volvió a hablar de él. Hizo un pozo en el patio y quemó sus cosas....todo. Es casi como si nosotros no hubiéramos tenido padre.

Y María, que sabrá jugarse por amor y confiar en la palabra de Pedro, no podrá ser feliz porque durante la ausencia de Pedro se descubre su embarazo, el que es celosamente ocultado en un pacto de silencio y de mentiras que fraguan los demás.

Inés, la cuñada estéril fingirá estar encinta, María deberá permanecer oculta en el sótano, lo que acepta convencida del pronto regreso de su enamorado que la llevará lejos de ese claustro. Pero Tomás, el hijo mayor, enfermo y formado para un ancestral pesimismo, desconfía y reniega de las cartas que arriban de Pedro, decidiendo ocultárselas a María.

Una noche de tormenta, la joven muere de sobreparto. Esta tragedia y la culpa irá destruyendo poco a poco a la familia.

El retorno de Pedro, aumenta la angustia. Poco puede hacer ese hombre destruido ante la presencia de un hijo inesperado y la pérdida de la mujer amada. Al día siguiente de su llegada desaparecerá para siempre, marchando a luchar en el frente italiano de la Primera Guerra.

Inés, la cuñada estéril, que ha seguido el juego para fingirse madre, es la promotora del estallido final, de la definitiva verbalización de tantas angustias calladas y de desgracias femeninas provocadas por el miedo a enfrentar lo "otro":

Inés (subiendo de tono) No digas nada ...no digas nada....no digas nada..Toda mi vida escuché esa maldita frase. Toda mi vida pensando en qué dirán los otros, que no se sepa esto, que no se sepa aquello...Quiero hablar, quiero gritar, me estoy ahogando en esta casa (en voz alta) Vecinos de la región (se pasea) Miren, acá está Inés, casada con el único hombre que conoció , destinada a la cocina, con el vientre seco y las ilusiones destruidas. En este momento renuncia a su sueño más amado, renuncia a ser la madre de esta criatura, porque no puede....(el llanto la puede) No puedo soportar el recuerdo de la verdadera madre que murió creyendo en el amor, en el amor que ninguno de nosotros fue capaz de darle.

El hilo conductor de la historia, a forma de coreuta narrativo, está a cargo del hijo menor, Santiago (Yaco), quien aparece al comenzar cada acto, para ir aportando al público la información que completan sus recuerdos y reflexiones y que le da a la puesta un carácter marcadamente subjetivo y autobiográfico.

Yaco, al comenzar la obra está partiendo para hacer el servicio militar. Ese alejamiento le otorga la distancia suficiente para aprender a valorar las virtudes transmitidas por la madre: valor del trabajo, sentido del esfuerzo cotidiano, importancia de la instrucción escolar, aprendizaje de la lengua local.

Así lo reconoce en la carta que les escribe:

...Al ver a tantos muchachos inferiores a mi en muchos aspectos, valoré la casa que tenia. La mayoria no sabe leer ni escribir, muchisimos nunca habian subido a un tren y tenian 
un miedo bárbaro. Algunos nunca habian salido del campo. Otros hablaban en sus dialectos provocando la risa de sus jefes. Pero habia uno que cuando le preguntaron el nombre de sus padres dijo: "el papa y la mama" porque asi los llamaban sin tener ni idea de los nombres que llevaban...

Pero además, el obligado exilio le permitirá tomar conciencia de la trascendencia que la fiera cerrazón materna ha provocado en las decisiones familiares y observar, impotente, el desmoronamiento de la precaria felicidad del grupo, simbolizada en ese escena primera en que la familia come alrededor de la mesa común. En su último relato se patentiza todo el dolor de esta tragedia tan íntima y, al mismo tiempo, tan común en las familias inmigradas:

Yo nunca pude olvidar aquella época en que éramos felices, y se preparaba la mesa para todos en la sala de los Benedetto y me parece mentira que todo sea nada más que un recuerdo (Empieza acción en el escenario con luces de colores)

Esta es la historia de nuestra familia, que hoy no sé por qué tenía ganas de contar. Ahora ustedes. ya la saben, pero por favor, creo que será mejor que no digan nada

(Música de piano. Yaco se incorpora a la escena. Toda la familia prepara la mesa y se sientan a comer. Todos están felices, ríen, hablan. Nadie está vestido de negro. Apagón lento)

La obra se cierra circularmente. Al comenzar, también la familia se encuentra reunida alrededor de la mesa, pero los vestidos negros y el silencio triste por la inminente partida del hermano, son la causa de la melancólica actitud, potenciada en la incapacidad o "imposibilidad" de exteriorizar los afectos que fue característica de estas familias dolorosamente insertadas en la nueva tierra. Un ciclo que ya prefigura una historia de desarraigo, privaciones y de utopias postergadas.

2. "LA BIUNDA". Autor: Carlos Carlino. Obra en tres actos estrenada el 11 de noviembre de 1953 por la Compañía Argentina de Comedia en el Teatro Lasalle de Buenos Aires.

Premio Argentores 1953. Segundo Premio Nacional 1956. Texto editado por Argentores. Ed. Del Carro de Tespis, Bs As, 1969

Las acotaciones escénicas iniciales, de neto corte realista, brindan la información cronotópica que permite al lector imaginar el espacio escénico y el contexto social donde se desarrollará la tragedia.

"Comedor de una casa de campo en 1910 con un flamante juego Renacimiento. El aparador a foro; el trinchante a la izquierda, la mesa en centro cubierta con una carpeta tejida a mano o hule. Sobre la mesa una frutera de marmolina. En las paredes fotografias de varios tamaños y reproducciones enmarcadas de naturalezas muertas..."

La meticulosidad de las indicaciones se corresponde a la intención del autor de situar al receptor en un momento preciso, 1910, año simbólico para visualizar una época en que ya se ha cumplido la primera etapa del proceso inmigratorio. Época en que aquellas primeras familias inmigrantes han podido superar los primeros esfuerzos agónicos de apropiación y conquista de 
la tierra y han empezado a vivir, ya crecidos los hijos, un período de bonanza basado no sólo en la explotación agrícola sino también pastoril.

Es otoño, ya han pasado dos meses desde la época comunitaria y festiva de la cosecha donde, se produce una "carnavalesca" atenuación de las costumbres.

La escenografía intenta generar la idea de un cierto bienestar y progreso. Progreso que justifica la búsqueda, a través de matrimonios por conveniencia, de una mayor estabilidad económica y mejoramiento de la "raza" por medio de valores visibles en la estética anatómica femenina.

La Biunda es apetecible, negociable, por la generosidad de sus caderas y sus pechos. Motivos que la posicionan como un ejemplar modelo de fertilidad. Y por ello, con mejores posibilidades "casoriables" que su "flaca" y por ende "seca" hermana mayor.

Checo: "La Biunda sí que es una mujer. Entusiasmado) Fuerte como una tierra nueva. (Biunda aparece en la escalera vestida de novia. Checo la ve, va a buscarla al pie de la misma, la toma de la mano y la pasea por la sala) Mirála: Es un orgullo! Parece la hija del conde de mi puebio. Tiene las caderas como una canasta. (La hace girar tomándola de la cintura) De esta canasta no se van a caer los panes de la vida! (La suelta y se aleja para mirarla) Mirá qué pechos.

Catalina: - Checo, estás borracho.

Checo: Seguro que sí!... Pero, mirá qué pechos! Justos para criar una docena de hijos...(Se acerca y trata de levantarle la pollera)

Biunda: - (impidiéndoselo) Papál....

Checo: - Soy el padre, caramba. (Le levanta la pollera hasta la pantorrilla) Mirá qué piernas: para sostener una raza entera de chacareros (La abraza. Redenta aparece en el balcón vestida para acompanarlos) Podrias dar más hijos que todas las mujeres de Salomón juntas, si quisieras.

Redenta: (mientras baja) Estás muy cariñoso, papá.

Checo: (volviéndose y señalando a Redenta con desagrado) En cambio ésa...Flaca de tanto tomar limón. Agria como leche cuajada. Te ponés a su lado y te enfermás, lo mismo que si durmieras a la sombra de una higuera.

Redenta: (con sonrisa malévola) Soy tu hija.

Esta es la causa de la desigual valoración que Checo hace de sus dos hijas y únicas herederas, pues Catalina, su esposa, no ha sabido cumplir con el ancestral mandato que obliga a la mujer a proporcionar fuertes brazos masculinos.

Las pautas culturales de las tradicionales familias italianas, de neto corte machista, no sólo otorgan el poder absoluto al hombre sino que ven en el nacimiento de hijos varones, la seguridad de la perpetuación de la progenie. Esta ancestral sobrevaloración de lo masculino justifica el absurdo deseo de Checo de un mundo sólo de varones y su percepción de lo femenino como origen y causa de las grandes calamidades que azotan a los hombres.

Checo: - (a Catalina, apuntándole con el dedo) Te dije cuando nació la Redenta...Basta de chancletas...Dame varones...dame varones....(áspero) Las mujeres son la ruina de la humanidad!....Mirá si tenía razón!...

Catalina:- (agobiada) Yo no elegí. Es Dios quien dispone. 
Checo: - Si yo fuera Dios haría que nacieran hembras entre los animales nada más. Alli si que rinden (paseándose) Mujeres....Mujeres....Gran suerte!.....

Pero la Biunda ha quedado encinta y no sabe cómo ya que "nadie me dijo" que estaba mal verse con un hombre en el campo. En su inocencia se niega a informar quien es el padre de ese hijo que ni siquiera sabe que lleva. Mientras para ella el drama es silenciar el nombre del enamorado, para los otros integrantes de la familia el drama es la comunidad que juzga.

Checo: (Furioso)- Cómo para qué? Para obligarlo a casarse con vos! Para que no tengamos un guacho en la familia, porca miseria!...

Redenta:- Para que no me señalen con el dedo y digan: ahi va la hermana de la que... Para lo que pensó ella. Lindo papel haremos cuando se sepa!

cabo?

Checo - (Deteniéndose a mirar a las mujeres) Y por qué tiene que saberse, al fin y al

Redenta - A la gente no se la engaña asi nomás.

Y para ello le buscan un novio, un hombre mayor con el que concordarán la boda como si fuera un negocio ya que el amor no es cosa de matrimonio.

Checo:- Con el corazón?...Salí de ahí...Qué tiene que ver el corazón?...

Catalina: Algo tiene que ver.

Checo: Vos me elegiste con el corazón?

Catalina: (con tristeza) Yo no...

Checo: (orgulloso) Yo, tampoco. Nos fue mal, si acaso?

Catalina: Creo que no.

Checo: Ahí está. El matrimonio lo hacen la costumbre y los hijos; para formar una buena pareja se necesita ser jóvenes y nada más.

La diferencia de tono en la mirada del hombre y la mujer señala la fuerza de lo "conveniente" por sobre lo "deseante".

Esa misma sintomática tristeza en la respuesta de Catalina, será permanente en la forma cómo la madre acompañará la tragedia de esas hijas destinadas al desamor y la soledad. Catalina ha enseñado a sus hijas como ella fue enseñada por dogmas seculares y en consecuencia aconseja a su hija frente al futuro marido:

Catalina: La mujer está para eso: para obedecer. En la casa manda uno solo: el hombre...A mi me enseñaron asi y yo hago lo mismo con mis hijas (A Biunda) Tenés que hacer lo que tu marido te diga. Todo en el matrimonio es una obediencia.

Pero los jóvenes, ya no piensan igual. Mientras se espera que baje la novia de su habitación los amigos chacotean, cantan y hay quienes logran besarse aprovechando la lejanía de los adultos.

Redenta, por su lado, aprovecha la confusión para, astutamente, sondear a los invitados y descubrir quien ha sido el enamorado de la Biunda. Bernal, un criollo, de profesión "Inspector 
de la langosta", cae en la trampa y aunque se lamenta de que esto le pasa por "meterme con gringas", al conocer la verdad del embarazo le propone a la Biunda escapar juntos.

El egoísmo y bronca de la Redenta que ve en el matrimonio de su hermana su fatal postergación (pues en esa comunidad si la hermana mayor no se casa primero, no se casa más) y las ambiguas palabras y actitudes del padre para con su hija menor a la que siente suya y así crió para su vejez: "Yo te cuidé para nosotros... Nunca pensé que nos dejarías..." serán la causa del fatal desenlace.

Consignamos por último este parlamento de Checo. En el mismo se hacen visibles, a través de la mirada crítica del autor, la hibridación de motivos y las razones de la exacerbada veneración de Checo por su hija menor. Ahora podemos comprender que la tristeza y preocupación de Catalina, la furia de la Redenta, tenían otra causa que la natural sensibilidad femenina ya había entrevisto: el padre ama incestuosamente a su hija menor porque posee las virtudes que a sus ojos la erigen en representante modélica de sus masculinos patrones afectivos: es "biunda" (rubia) y de ojos celestes como las mujeres del Paese natal y en ella se refleja, edipicamente, la sublimada imagen materna.

Checo: -Me diste un gran dolor cuando lo supe. Yo te quería para nosotros...Porque...porque sos igualita a como era mi mamá cuando era chico...Mi mamá era muy linda, así como vos... Vos no te acordás porque murió hace muchos años... Yo no hacia más que mirarla todo el dia....Qué linda era!... (La acaricia a medida que enumera) Tenía los ojos iguales a los tuyos...El pelo asi de rubio... Los brazos fuertes como un par de yugos.... asi como los tuyos....(Biunda sube un escalón, casi huyéndole y el padre la sigue) Vos hace mucho que no me abrazás....

\section{ADIOS, ADIOS, LUDOVICA. Autor: LERMO RAFAEL BALBI .}

Estreno: Rafaela (Pcia de Santa Fe) 1985. Obra premiada en el concurso de Obras Teatrales inéditas convocado por la Subsecretaría de Cultura de la Pcia de Sta Fe. (11) Texto publicado por el Ministerio de Educación y Cultura de la Pcia de Santa Fe en 1985. Santa Fe, Argentina.

La obra de Lermo Balbi ....pone en primer plano la temática inmigratoria presentándola bajo la luz de lo real maravilloso. En su obra el inmigrante y la inmigración no están vistos como simples fenómenos sociales o como gesta histórica: la realidad humana representada en la narración tiende a dar forma y sentido a significados más universales $y$ arquetípicos. El cielo de los días y las estaciones ligados a los ciclos de la vida del hombre y la búsqueda de la tierra prometida, son dos de los motivos primordiales recurrentes en su obra."

El texto dramático: Adios, adios, Ludovica es la reelaboración de un capítulo de su novela Continuidad de la gracia, ${ }^{12}$ Novela construida, según afirma Balbi en el prólogo,

\footnotetext{
11 Lenarduzzi, René. Filologia Moderna 10. Pacini Editore. Pisa, 1988

12 Balbi, Lermo Rafael: Continuidad de la gracia Gob. Pcia de Sta Fe y Rafaela. Sta Fe, 1995
} 
gracias a una infinita cantidad de fuentes orales y escritas que dejaron testimonio de la colonizacićn rural y que él mismo minuciosamente ficcionaliza.

Precisamente, la estructura particular de este texto se funda en la cantidad de documento insertados. Una palimpséstica parodia de géneros populares y oficiales: cartas personales, canciones en piemontés, apelos en francés que remedan aquellos afiches y publicitada: que se distribuían por las ciudades suizas incitando a las familias a emigrar a la tierra de la plata; páginas de libros escolares para enseñar las primeras nociones de lectoescritura, toxtos sociológicos que explican el fenómeno de la inmigración; poesías infantiles y capítulos enteros construidos en base a relatos orales que atesoran la historia personal de algunas fanilias de pioneros y que las sucesivas generaciones se encargaron de retransmitir.

El marco lo constituye un relato autobiográfico de 40 capítulos con cartas personales incluidas, escritos por una especie de alterego del autor que cuenta su propia experiencia de desarraigo 11 tener que abandonar siendo niño el espacio idílico del campo natal e ir a vivir con unos tíos de ciudad para iniciar su escolarización.

La hipotextual novela se inicia con una carta de la inmigrante Catalina Lucca de Maine a su hermano Simón Lucca donde le relata sus experiencias del viaje y las penurias y esperanzas depositadas en esta nueva tierra. En la misma, brinda al lector las primeras informaciones sobre Bernardo Racca y su familia, historia que volverá a ser retomada más adelante como capítulo incluido y que, reelaborada, será la matriz del hipertexto dramático de Adios, adios, Ludovica

En este párrafo, la voz femenino-materna, condensa los leit motiv recurrentes de la italianidad valor del trabajo, familia y religiosidad .

...Bernardo Racca, que vino a traer tu carta porque el primo llegó recién el quince, dice que $e_{1}$ oro de la Argentina está en los brazos de quienes ponen voluntad para trabajarle a la tierra, y eso es cierto, porque tanto en América como en Italia, si no se trabaja, nadie puede vivir ni hacer familia como Dios manda.

Al finalizar la novela, otra carta cierra el ciclo y es otra vez una voz materna, la madre del protagonista exiliado en Rafaela, quien le brinda noticias del pueblo: la tía Luisa, ya viuda, ha regresado al "aquí" del Corda natal y se ha encontrado en el viaje con Eulalia Viarenga (una nieta de Vita (Ludovica) Racca) que emigró a la ciudad y debió prostituirse para subsistir.

Fijate que el mundo es un pañuelo; en el ómnibus viajaba también la Eulalia Viarengo, la nieta de la Vita Racca, te acordás?.... La Eulalia en el camino le contó todo y le dijo que se venía de vuelta, pero no sé con qué cara va a mirar a la gente después de la vida que estuvo haciendo"

Los míticos mercachifles, Ismael y Pedro, arcángeles cocheros encargados de transportar el alma de Vica al final de Adios, adios Ludovica, hasta el Cielo donde la espera su esposo Bernardo, son también los cocheros de los que regresan al "aquí" del "paese natal". Ese mítico Corda, campesino omphalos-cuore materno, siempre dispuesto a recibir a los hijos pródigos. 
$V$ uelvo a doblar la carta, la pongo en el sobre, pienso en la tía Luisa y en la Eulalia, finalmente en los viejos mercachifles con su volantita de lata; hacía tiempo que nadie me decía nada de ellos, hasta creia que estaban muertos. Pero se ve que no.

Con estas palabras culminaba su novela, Lermo R. Balbi , un 30 de junio de 1977. Pero la historia de la historia no concluyó allí, sino que este texto, operó diez años después, como hipotexto de tres versiones dramáticas sucesivas, realizadas por el mismo Balbi y el director escénico: Antonio Germano, para trasponer al texto dramático definitivo a través de una elaborada operación de recorte y montaje, la historia de la estirpe Racca y su destino en la pampa gringa santafesina.

El lugar de la acción en la obra teatral, será la chacra de los Racca en Corda: espacio mítico inventado por Balbi para remedar Aráuz, su "paese" natal, particular espacio de la llanura santafesina donde se radicaron los colonos piemonteses después de la promulgación de la Ley de inmigración.

La escenografia, según sugerencias aportadas en el texto secundario, ambienta realísticamente una casa de campo con el típico patio y paisaje que sugiere con "indudable identidad la atmósfera abierta, iluminada y soledosa de nuestra planicie humifera, abundante en ganados y mieses, que los colonos italianos de entonces y sus hijos argentinos dieron carácter y destino".

La acción transcurre desde las primeras horas de la mañana al crepúsculo del último sábado de febrero de 1944 (período del año en que se cosecha la alfalfa) aunque los sueños y recuerdos de Ludovica, una anciana de más de 80 años, transfiguran tiempos y espacios, haciéndole confundir rostros y épocas, mientras espera la muerte que finalmente le traerá el merecido descanso a tantos años de fatiga y dolor.

En las_Noticias previas, el autor nos aporta elementos para comprender la densidad dramática de los acontecimientos, en relación con el contexto histórico político del país. 1944 es un año clave. Está por finalizar la Segunda Guerra Mundial y la contienda, si bien Argentina se mantuvo al margen, ha provocado su impacto haciendo disminuir la demanda de los productos agropecuarios.

Todavía quedan familias "al viejo estilo" gobernadas por los viejos paterfamilias de origen italiano que confían aún en los tiempos de bonanza del campo. Pero el ingreso de divisas por exportación de carnes y cereales se ha reducido frenéticamente y el país debe iniciar un acelerado proceso de industrialización. La industria manufacturera participa en el P.B.I. con un porcentaje mayor al de la agricultura y ganadería por lo que las ciudades se pueblan de fábricas y negocios que ofrecen hermosos señuelos a los hijos de los campesinos, quienes sueñan con emigrar a la ciudad.

Las sólidas familias campesinas empiezan a desintegrarse. La muerte del "pare" o "mare", factor todavía de cohesión, favorece la diáspora. La tierra familiar es subdividida y malvendida por los jóvenes herederos, que cansados de la esclavitud de la vida campestre, parten tras sueños de un destino mejor en las ciudades.

Adios, adios, Ludovica refleja ese momento de cambio en los campos santafesinos y su protagonista se convierte en el arquetipo femenino de una tierra humífera y de una época de promisión rural, ida para siempre tras los vientos de utopía del nuevo orden industrial. 
Una cronología de los personajes nos ayuda a comprender la conformación familiar. Ludovica, recluida en su cama-trono-carromato de dorado bronce, comanda aún la vida económica y cotidiana de la familia. Nada se realiza sin su supervisión o permiso y las cinco nueras funcionan como un coro griego siempre presto a ejecutar sus órdenes.

A través de los parlamentos vamos tomando conciencia de la fuerza de mando de la anciana que maneja con mano férrea y decide no sólo lo que se debe cocinar diariamente, cómo conservar lo que sobra, qué hacer con el trabajo del campo sino además, la cantidad de jabón que se debe usar para lavar, qué día de la semana se debe lavar, y si sus nietos adolescentes, pueden o no participar del habitual baile comunal de los sábados.

Ludovica.- Ustedes nunca consideran que una ya pasó los ochenta y que a esta edá los ojos no responden ni las orejas escuchan como antes. Si no sos la Fina, quién sos entonces, $y$ por qué lavan hoy que es sábado y no esperaron hasta el lunes como está dispuesto?

Eda: - Soy la Eda mare, y usté debe comprender que si se lavó hoy es por necesidá y no por otra cosa.

Ludovica: - Y qué necesidá es esa? Si hicieran las cosas como se debe, no tendrian que estar lavando y aprovecharian mejor el tiempo que en casa de pobres no se puede estar sin hacer nada

Eda:- Los hombres tienen más trabajo ahora...usté debe comprender que una no está queriendo hacer nada detrás suyo... sino lo que la vida manda en una casa de chacarero como nosotros.

Ludovica: Eso dicen cuando están delante mío: a mi espalda hacen y dicen lo que les gusta y no doy abasto con el control...Y apréndanlo nomás, como se lo digo siempre, que por más vieja que sea mi manera de pensar no la cambio, y saquen un ejemplo de lo que yo me ocupé en la crianza de mis hijos., y ellos sáben....lo que les aconsejó siempre esta viuda que desde los catorce años viene luchando para vivir como Dios manda a un cristiano y no como la gente criada a lo fino se le antoja...!

Al iluminarse la escena las nueras canta la "Preghiera di ragazza di quatordici anni mientras hacen las actividades domésticas. Melodía que sirve para dar unicidad a la obra al tiempo que sintetiza la historia personal de la protagonista quien, nacida en Cúneo, huérfana y criada por tíos paupérrimos, es casada a los catorce años con un hombre mayor, Bernardo Racca, que está por irse a "buscar el oro argentino" y promete volver a buscarla en un año.

Al iniciarse la acción, Vica niña canta en piemontés mientras acuna a su muñeca, esta popular plegaria donde se condensan los valores que toda mujer de 15 años debe esperar de su destino: un buen marido que le asegure una buena cama con sábanas de lino y el calor de un acolchado de plumas.
Pelegrin che andé a San Giaco, o preghé cul sant per mi! o preghé-lo di bun core, che mi daga un bün mari.
$C h$ 'a m'lo daga d'quindes ani, che quatordes j'ai gia mi.
Ch'a mi prunta na cambreta e'nt al mes ün bel letin;
e d'ün materass de piüma, y linsöi di tëila d'lin;
na cuverta di verdüra, tutta pienha di chichin!
$E$ trament che $m$ 'viro $e$ volto, $y$ chichín farán din din 
En sus delirios diurnos, la octogenaria Ludovica recuerda el rechazo de la niña por ese hombre maduro que ha regresado a buscarla para llevarla a un país lejano. Las penurias iniciales, el amor y respeto que va despuntando paralelamente a su maduración como mujer y como madre , el dolor y soledad por la temprana muerte del esposo y la energía que ejerció para llevar adelante casa y ocho hijos, desde su viudez a los 29 años.

Un inteligente juego lumínico perrnitirá ir trabajando los planos temporales y los diferentes espacios escénicos, alternando escenas de la vida de Ludovica: 1) su infancia en Cúneo y la propuesta de matrimonio mientras ella le canta nanas a su muñeca y llora para que el prometido no regrese de América a buscarla; 2) el viaje en barco y sus terrores ante ese futuro de lejanías y sacrificios, eternamente conjurados en la muñeca que acuna en sus brazos, y que será inmediatamente trocada, ni bien llegados a Corda, por su primer hijo, Bernandín. 3) El duelo de Bernardo con un criollo que la codicia, en el primer baile al que concurren; 4) la fotografía familiar pocos días antes de morir Bernardo, donde quedará impresa la memoria de la unión familiar, y 5) el presente de añoranza y esfuerzo continuo para mantener la cohesión de un universo que ya está manifestando los primeros síntomas de disgregación.

La utilización de un ciclorama para jugar escenas simultáneas que pertenecen a distintos planos temporales genera escenas que pueden ser encuadradas en el realismo mágico. Así la proyección de la fotografía de la familia con la inclusión de personajes vivos: Bernardo y el fotógrafo, mientras la cama es desplazada a un costado, y luego la proyección de la silueta de la volantita de los mercachifles volando por las nubes mientras Ludovica habla al fantasma de su marido muerto funden la realidad y la ficción, el presente y el pasado, haciendo trascender los planos de lo real para generar secuencias de fuerte contenido simbólico.

Particular relevancia, de entre todos los saltos en el tiempo, adquiere la escena de la llegada de los mercachifles Ismael y Pedro con la cama de bronce. Cama solar que funcionará como elemento de enlace de aquel pasado familiar prolífico con este presente terminal. Camacuna-ataud que circulará permanentemente delimitando los diferentes espacios escénicotemporales como símbolo irradiante de su ya anacrónico poder:

Ludovica: Oh Dios, para quién será tanta belleza!

Mujeres: (en coro) Para quién será tanta belleza!...

Ludovica: (alarmada, como frente a una locura) Oh no, Bernardo, es cama para gente rica y no para pobres chacareros como nosotros que esperan un hijo!

Ismael: -Qué creías Ludovica? que Bernardo no iba a pensar en darle a su mujer la cama que se merece para que tengan los hijos con que le vas a ayudar a hacer la familia que él espera?

Mientras Ludovica espera mansamente la muerte que llegará con el crepúsculo los demás esperan que se muera para cambiar de rumbo, agobiados por el rutinario y desesperante trabajo rural. La llegada de Ismael y Pedro abre un paréntesis de júbilo. La expectativa y frenesí que se genera en los jóvenes, se opone a la escena intimista del diálogo entre Ludovica e Ismael, que insta a la anciana a recordar su historia.

Ismael: ....A ver, cuál es la historia? me gustaría escucharla de nuevo...

Ludovica: - Era una nena que todavía jugaba con las muñecas y un día le dijeron que se tenía que casar con un hombre grande para venirse a América...." 
Progresivamente, con el esfuerzo del raconto, Ludovica va perdiendo las fuerzas y cambiando de tono pide a Ismael : “...Ismael, no puedo más. Usté ya sabe por qué...el corazón ya casi no golpea en el pecho.... Dígale a Bernardin que le termine la historia y que se la siga contando a sus hijos, y a los hijos de sus hijos..."

Voluntad de registro para que la historia no sea olvidada. Para que ese mundo dorado, ahora en decadencia, quede en la memoria de la simiente. Simbólicamente, el carro de los mercachifles va adquiriendo tonalidades doradas en escena mientras el pañuelo de seda italiano (único tesoro conservado por Ludovica en esos largos años de exilio) y el bastón (de mando) se deslizan de la mano de la muerta para retumbar quejumbrosamente en el piso.

La escena queda congelada y una voz profunda termina el relato: hecha las particiones de la tierra, los hijos que se van vivirán una vida de penurias y morirán enfermos de tuberculosis o hacinamiento en la fría y despersonalizada ciudad.

Los que se quedan son pocos y venden la herencia a capitalistas inescrupulosos para convertirse en peones-esclavos de nuevos dueños de esa tierra que una vez fue suya gracias al laborioso conservadorismo materno.

"Murieron sobre esta tierra, sí, pero ahora como peones de un nuevo dueño"

\section{A MODO DE CONCLUSIÓN:}

La profusión de obras que a lo largo del siglo han abordado el tema de la inmigración, dan cuenta de la trascendencia que este fenómeno ha dejado en el sentir y la cultura argentina. Pero es necesario destacar la producida en Santa Fe en zonas de fuerte inmigración y por escritores de $2^{\circ}$ y $3^{\circ}$ generación. Textos, sobre todo narrativos y dramáticos, que manifiestan esta común necesidad de recuperar la memoria farniliar y de ir, a través de la escritura, en búsqueda de ese tiempo "perdido" sin dejar de operar una mirada crítica que supera el tono épico y sublimatorio de la primera producción.

Interesante es también la voluntad de registro de formas lingüísticas dialectales que todavía perviven en uso y en la capacidad comprensiva de los descendientes de esos grupos inmigratorios.

En el caso de Dis pa gnente aparece no sólo corroborado en el título, sino también en la inclusión de numerosos modismos y vocablos con absoluto respeto a la grafia de origen como las expresiones jaltro che!, ora mai, y los apelativos: mare, pare, barba (tío), así como en denominaciones atributivas que entraron en nuestro acerbo lingüístico como machorra (estéril), en nombres tardíamente españolizados: Yaco por Giaco, y en italianismos incorrectamente consignados: fola por folla (loca),

En "La Biunda", si bien es menos manifiesta la voluntad de registro lingüístico ya que Carlino descontextualiza a sus personajes al hacerlos hablar un español extrañamente culto, deja particularizado su origen a través de los nombres y sobrenombres, Redenta: Biunda, Angela Checo, y en expresiones dialectales dosificadas a lo largo de los parlamentos: "porca miseria", "sacardie", "porca vita", "la pipeta", "altro qué".

Como vemos en todos los casos, han sido transportados a la grafía española. 
Adios, adios, Ludovica es la más elaborada en este sentido y hay en Lermo Balbi una marcada intencionalidad de representar la forma de hablar característica de estas comunidades.

Esta obra comparte con las anteriores la inclusión de apócopes de nombres italianos: Yeppe (apócope de Giuseppe); Vica (Ludovica), Chun etc, pero se diferencia por la transcripción de esa interlingua generada en el contacto del dialecto italiano de origen (cuya pureza se va perdiendo por falta de contacto con la lengua viva) y el idiolecto español típico de la zona rural. De allí la alternancia de apócopes dialectales rurales: alfa (alfalfa); con apelativos que intentan conservar en su grafia la pronunciación de origen: marin-na; con otros definitivamente españolizados como nona en vez de nonna. Balbi elabora también escenas bilingües cantadas simultáneamente como por ejemplo cuando Ludovica canta nanas en piemontés al hijo recién nacido, y Bernardo y amigos festejan el nacimiento cantando en italiano: "Bevono nostri padri / Si!! / Bevono nostri madri?/ Si/ E noi che figli siamo, beviamo, beviamo!!"

Pero la transposición del habla del inmigrante, se manifiesta fundamentalmente en la pronunciación cortada, en ejemplos de transferencia morfológica: usté, ansiedá, edá, ciudá, (no pronunciación de las "d" finales por asimilación del fenómeno de troncamento italiano), y en la alternancia del tú- vos/Uduted (Lei / tu: registro formal/informal) como se ve en este ejemplo:

Bernardo: .Cristo Ludovica, aqui estoy! Vine a buscarte aunque me hayas devuelto el pasaje. Es cierto que la gente de Cúneo es porfiada pero el más porfiado soy yo....(Tono imperativo) Vica, espero tu palabra! Se casa conmigo quiera o no quiera!...Crucé el mar para buscarte! (Pausa, con menos convicción) Te casás quieras o no quieras! (Pausa, derrotado casi implorando) Entonces no, Ludovica? Qué hago, me vuelvo solo?"

Así como de refranes, expresiones y canciones que atesoran el saber colectivo y las comunes visiones de mundo traídas hace más de un siglo del Piemonte natal.

Las obras analizadas son sólo un mínimo exponente, en cantidad, no así en calidad, de esta visceral y privada epopeya. Como Virgilios contemporáneos, nos vemos también impelidos a escribir nuestra propia Eneida, a reconstruir el relato mítico de la diáspora sufrida desde aquella nuestra Madre-Troya original: Italia, esa otra madre patria. 


\section{Datos bio-bibliográfico de los dramaturgos:}

BALBI, OSCAR: ingresó al grupo vocacional EPSILON de la ciudad de San Jorge, en calidad de actor a fines de 1977 y en 1987 fue elegido director del mismo. Realizó estudios de expresión corporal, mimo y expresión artística y ha representado entre otros, los personajes de la nona en la obra homónima y del abuelo de "Gris de ausencia", ambas de Roberto Cossa.

En 1993 se puso en escena otra de sus obras "Sin evidencias" y fue elegido para dirigir el Centro de Teatro Independiente de Sastre, Santa Fe.

Actualmente, dirige y actúa ambos grupos.

CARLINO, CARLOS: nació en Oliveros, provincia de Santa Fe en 1930 y murió en Buenos Aires. Su obra abarca una importante producción en poesía, teatro, ensayo y periodismo. Recibió numerosos premios nacionales e internacionales tanto por su obra poética como por su dramaturgia y se destaca entre sus contemporáneos por haber planteado con sobrio estilo y profundidad problemáticas tanto urbanas como rurales de su provincia pero en especial del ámbito de la pampa gringa.

Entre sus obras mencionamos: Producción Lírica: Cara a cara (1933); Vecindades (1935); Poemas de la tierra (1938); Poemas con labradores (1940); La voz y la estrella (1945); Patria Litoral (1946); dramática: La Biunda (1945); Cuando trabaje (1946) Tierra del destino (1951); Un cabello sobre la almohada; Las andanzas de Juan Tordo(teatro para niños); Esa vieja serpiente engañadora; y ensayo: Biografias en gringos (1975); Los gauchos y los gringos en la tierra ajena (1976)

BALBI, LERMO RAFAEL: Nació en Rafaela, colonia agraria de la Prov. de Santa Fe en 1931 y murió en Santa Fe en 1988.

"Todos mis antepasados sin excepción fueron campesinos. La tierra, los cielos del tiempo la labor agricola, necesariamente fueron los temas fundamentales donde transcurrió mi niñez". Su obra ha tenido la intención de evocar el lejano "paraíso perdido" de su niñez en el pueblo de Arauz, el que recrea en el mítico "Corda" y de rescatar del fondo del olvido la memoria colectiva de los núcleos que señaron la inserción de la estirpe piemontesa en Argentina. La temática de su obra narrativa, poética y teatral, resalta la inocencia del tiempo pasado, el de la gente sencilla, la cohesión familiar y la dimensión trascendente y comunitaria de la vida.

Es autor de libros de poesía:_El hombre transparente (1966), La Tierra viva (1972) Arauz, muerto y celeste (1979); cuentos: Los días siguientes (1970) 3 cuentos (1983) y novela: Los nombres de la tierra (1985) y Continuidad de la gracia (inédita durante mucho tiempo y editada por el Gob. Pcial en 1985. Adios, adios, Ludovica, estrenada en 1985 en Rafaela bajo la dirección de su director Antonio Germano y vuelta a montar en el Teatro Nacional Cervantes de Bs As en 1986 es repuesta anualmente en Santa Fe y en el interior de la provincia. Especialmente en ocasión de la visita de delegaciones del Piemonte para la firma de "gemelleggio" con comunidades pares santafesinas. 